\title{
Etoposide radiosensitizes p53-defective cholangiocarcinoma cell lines independent of their $\mathbf{G}_{2}$ checkpoint efficacies
}

\author{
ARUNEE HEMATULIN ${ }^{1}$, SUTIWAN MEETHANG ${ }^{1}$, \\ KITSANA UTAPOM ${ }^{2}$, SOPIT WONGKHAM ${ }^{3}$ and DANIEL SAGAN ${ }^{4}$ \\ ${ }^{1}$ Radiobiology Research Laboratory, Department of Radiation Technology, Faculty of Allied Health Sciences; \\ ${ }^{2}$ Radiation Oncology Unit, Department of Radiology, Faculty of Medicine, Naresuan University, Phitsanulok 65000; \\ ${ }^{3}$ Department of Biochemistry, Liver Fluke and Cholangiocarcinoma Research Center, Faculty of Medicine, \\ Khon Kaen University, Khon Kaen 40002, Thailand; ${ }^{4}$ Independent Researcher, Miesbach, D-83714 Bavaria, Germany
}

Received May 6, 2017; Accepted November 2, 2017

DOI: $10.3892 / \mathrm{ol} .2018 .7754$

\begin{abstract}
Radiotherapy has been accounted as the most comprehensive cancer treatment modality over the past few decades. However, failure of this treatment modality occurs in several malignancies due to the resistance of cancer cells to radiation. It was previously reported by the present authors that defective cell cycle checkpoints could be used as biomarkers for predicting the responsiveness to radiation in individual patients with cholangiocarcinoma (CCA). However, identification of functional defective cell cycle checkpoints from cells from a patient's tissues is cumbersome and not applicable in the clinic. The present study evaluated the radiosensitization potential of etoposide in p53-defective CCA KKU-M055 and KKU-M214 cell lines. Treatment with etoposide enhanced the responsiveness of two p53-defective CCA cell lines to radiation independent of $\mathrm{G}_{2}$ checkpoint function. In addition, etoposide treatment increased radiation-induced cell death without altering the dominant mode of cell death of the two cell lines. These findings indicate that etoposide could be used as a radiation sensitizer for $\mathrm{p} 53$-defective tumors, independent of the function of $\mathrm{G}_{2}$ checkpoint.
\end{abstract}

\section{Introduction}

Radiotherapy has been identified as the most common cancer treatment over the past decades; it has been estimated that over half of all cancer patients will receive radiotherapy during the course of their treatment (1). Unfortunately, the efficacy of this treatment modality is low in several malignancies due to the resistance of cancer to radiation $(2,3)$. Ionizing radiation

Correspondence to: Dr Arunee Hematulin, Radiobiology Research Laboratory, Department of Radiation Technology, Faculty of Allied Health Sciences, Naresuan University, 99 Moo 9, Phitsanulok-Nakhon Sawan Road, Tha Pho, Phitsanulok 65000, Thailand

E-mail: aruneeh@nu.ac.th

Key words: radiosensitizer, etoposide, cell cycle checkpoint, cancer primarily eradicates cancer cells by damaging the DNA of irradiated cells (2). Nevertheless, the radio-responsiveness of cancer cells is modulated by multiple mechanisms, including cell cycle checkpoint function, DNA repair and cell death pathways $(2,4,5)$.

Cell cycle checkpoints function as the 'guardians' of the cell in response to DNA damage and serve a critical role for cell survival following exposure to radiation $(6,7)$. Radiation-induced DNA damage triggers cell cycle checkpoints to halt cell cycle progression. This allows for the repair of damage or promotes death of cells with unrepaired DNA damage (7). The majority of cancer types exhibit defects in cell cycle checkpoints, leading to resistance to radiotherapy (8). The proficiency of the cell cycle checkpoints determines the sensitivity of cancer cells to anticancer treatment. Thus, it is highly likely that the proficiency of cell cycle checkpoints is a potential biomarker for predicting radiation and drug responses of tumors. Targeting cell cycle checkpoint defects is being discussed as the next generation of anticancer therapy (9). This therapeutic approach relies on defective checkpoints in cancer cells and sensitizes them to radiation therapy (10-12). Investigating checkpoint defects and the synthetic lethal targeting of defective checkpoints in cancer cells may represent a promising approach for increasing the efficacy of radiotherapy for individual cancer patients.

Recently, it was reported by the present authors that three human cholangiocarcinoma (CCA) cell lines, with variances in cell cycle defects, differed markedly in their radiation sensitivities. The different radiation sensitivities were associated with existing $\mathrm{G}_{1}$ or $\mathrm{G}_{2}$ checkpoint defects in the analyzed cells (10). CCA cells with an intact $\mathrm{G}_{1}$ checkpoint were the most sensitive cells to radiation. CCA cells with a defective $G_{1}$ checkpoint but intact $\mathrm{G}_{2}$ checkpoint were the most radio-resistant cells. Furthermore, inhibition of checkpoint kinase 1/2 (Chk1/2) selectively enhanced the radiation sensitivity of CCA cells with a defect in the $G_{1}$ checkpoint. This indicated that defective cell cycle checkpoints might be used as biomarkers for predicting the responsiveness to radiation in individual CCA patients.

Frequently, cancer cells encompass defects in $\mathrm{G}_{1}$ checkpoints due to a loss of $\mathrm{p} 53$ function, resulting in resistance to 
radiation treatment (13). The targeting of $\mathrm{G}_{2}$ checkpoint functions effectively enhanced the radio-sensitivity of cancer cells with defective $\mathrm{G}_{1}$ checkpoints but intact $\mathrm{G}_{2}$ checkpoints $(11,12)$. Our hypothesis is that cancer cells defective in the $G_{1}$ and $G_{2}$ checkpoints would not be radiosensitized by targeting of the $\mathrm{G}_{2}$ checkpoint. Thus, it is crucial to identify the cell cycle checkpoint defects for the application of synthetic lethal targeting of cell cycle checkpoints. However, the identification of checkpoint defects using individual patient tissue is cumbersome and not clinically applicable. Thus, the present study sought a substance capable of sensitizing $\mathrm{G}_{1}$ checkpoint-defective cell lines independent of the status of their $\mathrm{G}_{2}$ checkpoints.

Etoposide has been widely used as an anticancer chemotherapeutic drug (14). Etoposide induces DNA double-strand breaks during the $S$ and $G_{2}$ phases of the cell cycle via inhibition of DNA topoisomerase II activity (15). It is highly likely that etoposide-induced DNA damage prior to irradiation renders cancer cells more vulnerable to the effects of radiation. Therefore, the present study investigated whether etoposide enhances radiation sensitivity of cells from two p53-defective CCA cell lines with $\mathrm{G}_{1}$ checkpoint defects, which differ in their $\mathrm{G}_{2}$ checkpoint status.

\section{Materials and methods}

Cell culture. The two CCA cell lines KKU-M055 (JCRB1551) and KKU-M214 (JCRB1556), and MMNK1 (JCRB1554) were obtained from Japanese Collection of Research Bioresources Cell Bank (Tokyo, Japan). KKU-M055 was established from a poorly differentiated adenocarcinoma tumor of a CCA patient. KKU-M214 was established from the moderately differentiated adenocarcinoma of a CCA patient. MMNK1 was established from immortalized normal human cholangiocytes (16). The human cervical carcinoma cell line (SiHa; ATCCHTB-35) was a gift from Dr D. Nantajit (Chulabhorn Hospital, Bangkok, Thailand). MMNK1 and SiHa were used as reference cell lines, due to their expression of full-length p53 $(16,17)$.

The cells were cultured in Dulbecco's modified Eagle medium (Gibco; Thermo Fisher Scientific, Inc., Waltham, MA, USA), containing $2.5 \mathrm{mM}$ L-glutamine, $10 \%$ fetal bovine serum (Gibco; Thermo Fisher Scientific, Inc.), 0.25\% sodium bicarbonate supplemented with 100 units/ml penicillin, $100 \mu \mathrm{g} / \mathrm{ml}$ streptomycin, and $0.25 \mu \mathrm{g} / \mathrm{ml} \mathrm{Amphotericin} \mathrm{B}$ (Gibco; Thermo Fisher Scientific, Inc., Waltham, MA, USA). The cells were incubated in a humidified incubator at $37^{\circ} \mathrm{C}$ and $5 \% \mathrm{CO}_{2}$.

Cell irradiation and treatments. Exponentially growing KKU-M055 and KKU-M214 cells were seeded into 6-well plates, $\sim 5 \times 10^{4}$ cells/well. The cells were irradiated with a single dose of $0,2,4$ or 6 Gy of X-rays generated by a $6 \mathrm{MV}$ linear accelerator (Varian 2100CD, Varian Medical Systems, Palo Alto, CA, USA). The source-to-sample distance was $100 \mathrm{~cm}$. Following irradiation, cells were incubated at $37^{\circ} \mathrm{C}, 5 \% \mathrm{CO}_{2}$ in a humidified atmosphere. For etoposide treatment, the cells were treated with 0.025 or $0.05 \mu \mathrm{g} / \mathrm{ml}$ etoposide (Selleck Chemicals, Houston, TX, USA) for $24 \mathrm{~h}$. Next, the cells were irradiated as aforementioned and subsequently collected at different time points as indicated in the applicable figures for further analysis.
Clonogenic cell survival assays. KKU-M055 and KKU-M214 cells were seeded in triplicate into wells of 6-well plates. The number of cells seeded per well varied with the dose of radiation administered. The number of cells for radiation doses of 0 , 2 , 4, or 6 Gy were 100, 200, 400, or 600, respectively. The cells were irradiated with a single dose of $0,2,4$ or 6 Gy. The cells were then allowed to grow for 10-14 days until the surviving cells produced macroscopically visible colonies. The cells were then fixed with $95 \%$ ethanol for $10 \mathrm{~min}$ at room temperature and then stained with $0.4 \%$ Giemsa solution for $10 \mathrm{~min}$ at room temperature. Colonies were analyzed using light microscopy (magnification, $\mathrm{x} 10$ ). Colonies containing $>50$ cells were counted, and survival fractions were calculated as ratios of the number of colonies formed from treated and untreated cells, corrected for the plating efficiency of unirradiated cells.

Cell cycle analysis. A total of $\sim 8 \times 10^{4}$ cells/well were seeded into 6 -well plates and incubated in a humidified incubator at $37^{\circ} \mathrm{C}$ and $5 \% \mathrm{CO}_{2}$ for $12 \mathrm{~h}$. At $24 \mathrm{~h}$ prior to irradiation, the cells were pretreated with $0.05 \mu \mathrm{g} / \mathrm{ml}$ etoposide. Next, the pretreated cells were irradiated with a single dose of 4 Gy of $\mathrm{X}$-rays as aforementioned and collected at 24 or $48 \mathrm{~h}$ following irradiation. Propidium iodide (PI) staining of isolated nuclei for cell cycle analysis was performed as described previously (18). The suspension of PI-stained, isolated nuclei was analyzed with a flow cytometer (Cytomics FC500-MCL with CXP 2.2 software; Beckman Coulter, Inc., Indianapolis, USA).

Western blot analysis. Total protein was extracted from cells at indicated time points following each treatment as described previously (18). A total of $30 \mu \mathrm{g}$ protein per lane from each sample were separated by electrophoresis using 8,10 or $12 \%$ SDS-PAGE and electroblotted onto polyvinylidene difluoride membranes. The membranes were blocked in TBST containing $5 \%$ skimmed milk for $1 \mathrm{~h}$ at room temperature. Next, the membranes were probed with a primary antibody diluted in $3 \%$ bovine serum albumin (Santa Cruz Biotechnology, Inc., Dallas, TX, USA) in TBST overnight at $4^{\circ} \mathrm{C}$. Subsequent to washing three times with TBST, the membranes were incubated with a horseradish peroxidase-labeled secondary antibody diluted in TBST containing 3\% skimmed milk at room temperature for $1 \mathrm{~h}$. The membranes were washed three times with TBST, and the immunoreactivity was detected using chemiluminescence (Luminata Crescendo Western HRP substrate; Merck KGaA, Darmstadt, Germany) with a digital phosphorimager (Chemi Doc ${ }^{\text {TM }}$ XRS+Image Lab ${ }^{\text {TM }} 5.1$ software, Bio-Rad Laboratories, Inc., Hercules, CA, USA). The following antibodies were used: Anti-p53 (A01767; 1:1,000; Genscript, Piscataway, NJ, USA); anti-actin (sc1616; 1:1,000) and anti-goat Immunoglobulin (Ig)G horseradish peroxidase (HRP)-conjugated (sc2020; 1:3,000) were both purchased from Santa Cruz Biotechnology, Inc; anti-phospho-Chk2 Thr68 (2197; 1:1,000), anti-phospho-Wee1 Ser642 (4910; 1:1,000), anti-phospho-p53 Ser15 (9286; 1:1,000), anti-phospo-Cdc2 Tyr15 (4539; 1:1,000), anti-p21 (2947; 1:1,000), anti-PARP (9542; 1:1,000), anti-cleaved PARP (5625; $1: 1,000)$, anti-Caspase-3 (9665; 1:1,000), Cleaved Caspase-3 (9664; 1:1,000), anti-mouse IgG HRP-linked (7076; 1:3,000), anti-rabbit IgG HRP-linked (7074; 1:3,000) were purchased from Cell Signaling Technology, Inc., Danvers, MA, USA. 
Nuclear staining and fluorescence microscopy. Approximately $1 \times 10^{4} \mathrm{KKU}-\mathrm{M} 055$ and KKU-M214 cells were seeded on glass cover slips and cultured in 6 -well plates overnight at $37^{\circ} \mathrm{C}$ with $5 \% \mathrm{CO}_{2}$. The cells were pretreated with $0.05 \mu \mathrm{g} / \mathrm{ml}$ etoposide for $24 \mathrm{~h}$. Next, the cells were irradiated with $4 \mathrm{~Gy}$ of X-rays or not irradiated. At each indicated time point, the cells seeded on cover slips were washed briefly with PBS and stained with $8 \mu \mathrm{M}$ Hoechst 33342 in darkness at room temperature for $5 \mathrm{~min}$. The stained cells were washed with PBS and then mounted with anti-fade solution for fluorescence microscopy (Zeiss HBO100 microscope Illuminating System Axiovision Rel 4.8; Carl Zeiss AG, Oberkochen, Germany). The mode of cell death was evaluated according to the characteristic nuclear morphologies. Apoptotic cells were scored from cells containing bright nuclear staining with apoptotic bodies, nuclear condensation and fragmentation, as previously described (19). Mitotic catastrophic cells were scored from cells containing multiple micronuclei, multinucleated and multilobulated nuclei, as previously described $(19,20)$. Senescent cells were scored from cells containing nuclei with senescence-associated heterochromatic foci, as previously described (18). The number of apoptotic, mitotic catastrophic or senescent cells was quantified by counting $\geq 800$ cells for each experiment. The relative number of cells for each mode of cell death was expressed as percentage of the total number of counted nuclei.

Statistical analysis. Data are presented as the mean \pm standard deviation of at least three independent experiments. Mean and standard deviation were calculated using the integrated functions in Microsoft Excel 2016 (Microsoft Corporation, Redmond, WA, USA). Trend lines were also generated using integrated functions in Microsoft Excel.

Comparisons of D37 values (radiation dose at which 37\% of cells survive compared to untreated cells) for each etoposide pre-treatment group and etoposide untreated control group were performed using SPSS (version 17.0; SPSS, Inc., Chicago, IL, USA). Means of D37 values were calculated from three independent experiments for each treatment group and each cell line. One way analysis of variance (ANOVA) with Bonferroni post hoc testing was used for P-value calculations. $\mathrm{P}<0.05$ was considered to indicate a statistically significant difference.

\section{Results}

Sensitivity of KKU-M055 and KKU-M214 cell lines to radiation. The present study assessed the radiosensitivity of the KKU-M055 and KKU-M214 CCA cell lines. Clonogenic survival assays were performed following X-ray irradiation. Cell survival curves were plotted and the D37 values were calculated. As shown in Fig. 1A, the D37 values of KKU-M055 and KKU-M214 cells were 3.61 and $2.92 \mathrm{~Gy}$, respectively. This result indicates that the poorly differentiated adenocarcinoma cell line KKU-M055 is more resistant to radiation compared with the moderately differentiated adenocarcinoma cell line KKU-M214.

p53 protein status in KKU-M055 and KKU-M214 cell lines in response to radiation. The levels of $\mathrm{p} 53$, a crucial protein involved in DNA repair, cell cycle arrest and cell death pathways, were evaluated (Fig. 1B and C). It was previously reported by the present authors that KKU-M055 and KKU-M214 CCA cell lines express truncated, not full-length p53 (10). The result of the present study is consistent with this previous report (Fig. 1B). Accumulation and activation of p53 are crucial for the function of p53. In response to DNA damage, p53 is phosphorylated at Ser15 by serine-protein kinase ATM. Ser15 phosphorylation contributes to the stabilization of p53 and initiates additional phosphorylation of p53 that contribute further to p53 induction and activation (21). An accumulation of the truncated p53 protein in KKU-M055 cells following irradiation was hardly observed (Fig. 1C). The phosphorylation of p53 at serine 15, which is crucial for p53 stabilization and activation, was undetectable in KKU-M055 cells. Similarly, the p53 target gene product, p21, which is crucial for the induction of cell cycle arrest, was also undetectable in KKU-M055 cells (Fig. 1C). Collectively, the absence of full-length p53 expression, $\mathrm{p} 53$ accumulation, induction of Ser15 phosphorylation of p53 and expression of p21 in response to radiation indicates that $\mathrm{p} 53$ is non-functional in response to radiation damage in KKU-M055 cells.

The level of truncated p53 protein in KKU-M214 cells was very low, and the accumulation of $\mathrm{p} 53$ following radiation damage was not observed (Fig. 1B and C). By contrast, the phosphorylation of p53 at Ser15 was markedly increased in KKU-M214 cells following radiation damage. Nevertheless, induction of p21 was hardly noticed. This observation indicates the partial activation of the p53-p21 axis in response to radiation.

Proficiencies of $G_{2}$ checkpoints in KKU-M055 and $K K U-M 214$ cells in response to radiation. Proficiencies of $\mathrm{G}_{2}$ checkpoints in KKU-M055 and KKU-M214 cells were evaluated by cell cycle analysis and determination of the levels of proteins involved in $\mathrm{G}_{2}$ checkpoint signaling. The doubling times of KKU-M055 and KKU-M214 cells were 23-25 h. Obchoei et al (22) and Wattanawongdon et al (23) had reported similar doubling times of KKU-M055 and KKU-M214 cells, respectively $(22,23)$. Therefore, the cell cycle distribution profiles of the two cell lines were analyzed at 24 and $48 \mathrm{~h}$ following irradiation (Fig. 2A). A radiation-induced $\mathrm{G}_{2} / \mathrm{M}$ block was clearly demonstrated in KKU-M055 cells by an increase of the $\mathrm{G}_{2} / \mathrm{M}$ population from 23 to $45 \%$ at $24 \mathrm{~h}$ following irradiation. The $\mathrm{G}_{2} / \mathrm{M}$ population of KKU-M055 cells slightly decreased from 45 to $40 \%$ at $48 \mathrm{~h}$ following irradiation, which remained markedly higher compared with the control cells. Phosphorylation of Chk2 at Thr68, Weel-like protein kinase (Wee1) at Ser642 and Cdc2 at Tyr15 were clearly observed in KKU-M055 cells (Fig. 2B). Notably, the level of cyclin $\mathrm{B} 1$, which is expressed predominantly during $\mathrm{G}_{2} / \mathrm{M}$ phase, markedly increased at $24 \mathrm{~h}$ following irradiation in KKU-M055 cells. After $24 \mathrm{~h}$ ( $48 \mathrm{~h}$ after irradiation), protein levels slightly decreased (Fig. 2C). These findings support the results of the cell cycle analyses. Together with the p53 and p21 expression data, this indicates the presence of an intact radiation-induced $\mathrm{G}_{2}$ checkpoint independent of the p53-p21 axis in KKU-M055 cells.

By contrast, the proportion of KKU-M214 cells in the $\mathrm{G}_{2} / \mathrm{M}$ phase was not increased, as determined at 24 and 
A

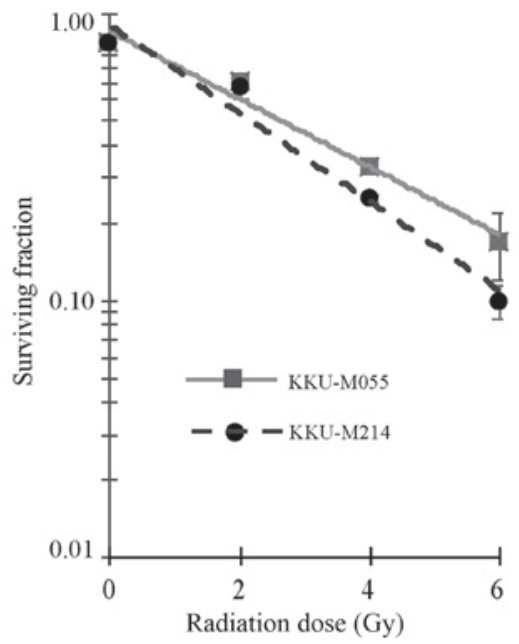

B

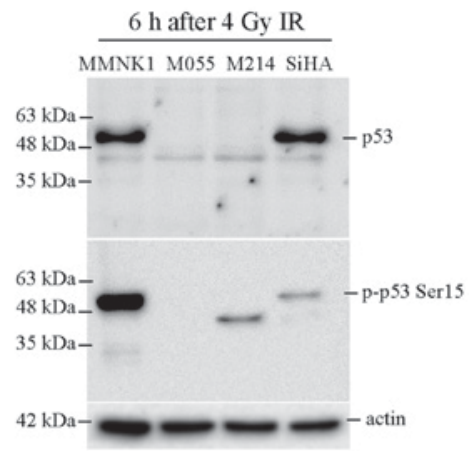

C

Time following irradiation

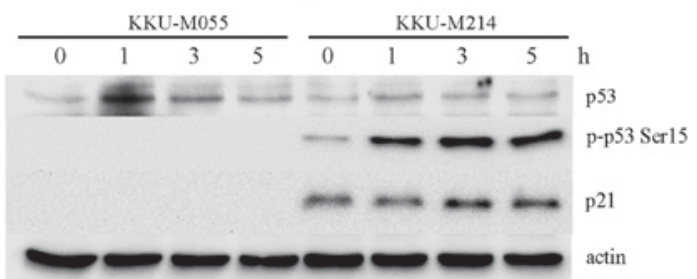

Figure 1. Radiation response of cholangiocarcinoma cells. The radiosensitivities of KKU-M055 (solid line) and KKU-M214 (dashed line) cells were obtained from clonogenic survival assays. Survival fractions were determined at day 10 following X-ray irradiation. (A) The dose-response curves indicate the mean \pm standard deviation of survival fractions of three independent experiments. (B) The levels and molecular weights of p53 and p-p53 Ser15 proteins were determined by western blot analysis of extracts from irradiated MMNK1, KKU-M055 (M055), KKU-M214 (M214) and SiHa cells, which were prepared $6 \mathrm{~h}$ following irradiation with 4 Gy X-rays. (C) The levels of p53, p-p53 Ser15 and p21 in extracts of KKU-M055 and KKU-M214 cells, which were prepared at the indicated time points following irradiation with 4 Gy X-rays. The detection of $\beta$-actin was used as a loading control. p-p53 Ser15, tumor protein p53 phosphorylated at Ser15; p21, cyclin-dependent kinase inhibitor 1A.

$\mathbf{A}$
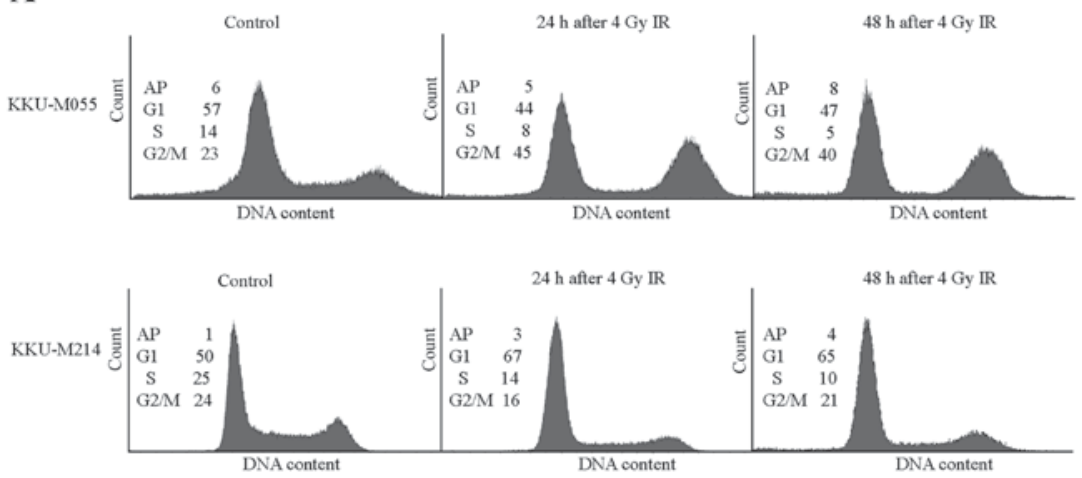

B

Time following irradiation

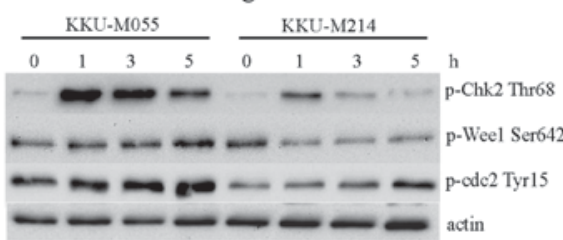

C

Time following irradiation

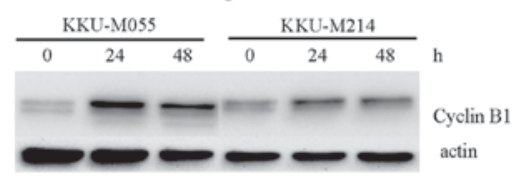

Figure 2. Proficiencies of $\mathrm{G}_{2}$ checkpoints in KKU-M055 and KKU-M214 cells in response to radiation. The cells were irradiated with 4 Gy X-rays and collected at different time points for protein extraction and cell cycle analysis. (A) The cell cycle distribution profiles were analyzed by flow cytometry. The numbers in the histograms indicate the percentages of the cells in each phase of the cell cycle $\left(\mathrm{G}_{1}, \mathrm{~S}_{\mathrm{and}} \mathrm{G}_{2} / \mathrm{M}\right)$ or $\mathrm{AP}$. (B and C) The levels of relevant proteins for $\mathrm{G}_{2}$ checkpoint signaling were determined by western blot analysis. The detection of actin was used as a loading control. AP, aneuploidy; IR, irradiation; p-Chk Thr68, checkpoint kinase 2 phosphorylated at Thr68; Wee1, Weel-like protein kinase; Cdc2, cyclin-dependent kinase 1. 
A

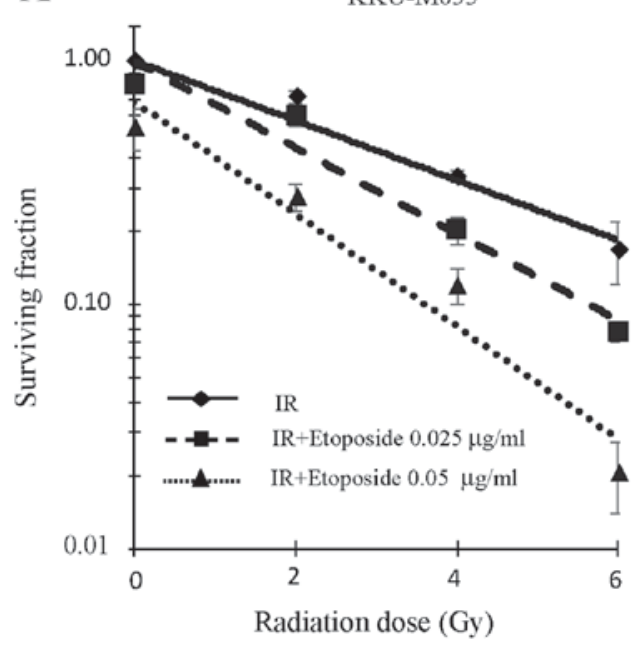

B

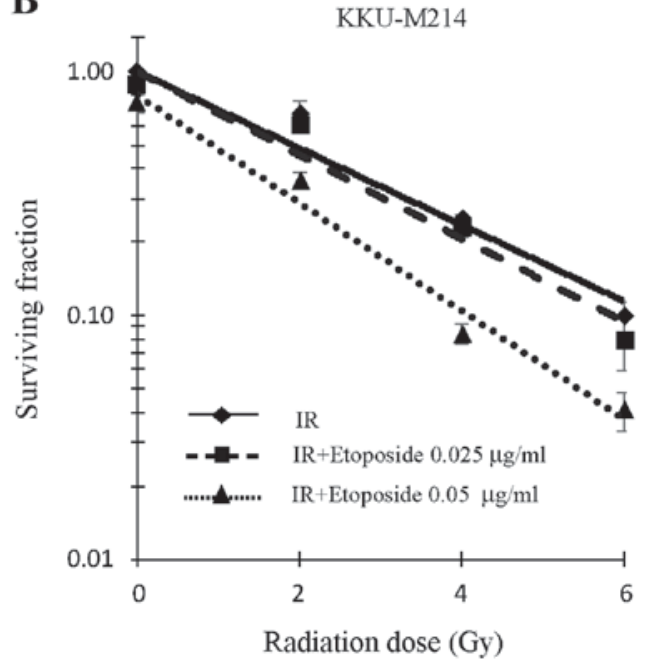

Figure 3. Effects of etoposide on the radiosensitivities of cholangiocarcinoma cell lines. The cell survival curves of (A) KKU-M055 and (B) KKU-M214 cells were obtained from clonogenic survival assays. The cells were treated with X-ray irradiation or etoposide $(0.025$ or $0.05 \mu \mathrm{g} / \mathrm{ml})$ alone or pretreated with etoposide for $24 \mathrm{~h}$ prior to X-ray irradiation. Survival fractions were determined at day 10 following X-ray irradiation. The dose-response curves depict the mean \pm standard deviation of survival fractions of three independent experiments. IR, irradiation.

A

Time following etoposide treatment

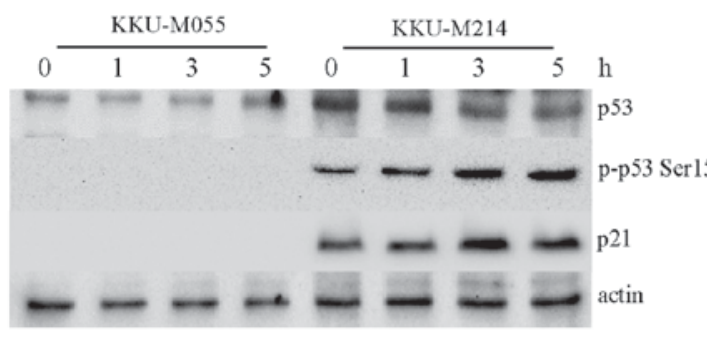

C

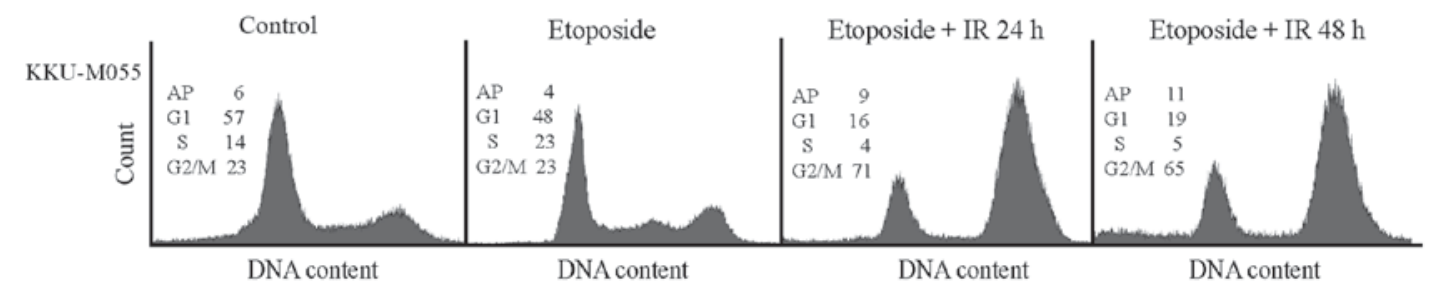

B

Time following etoposide treatment

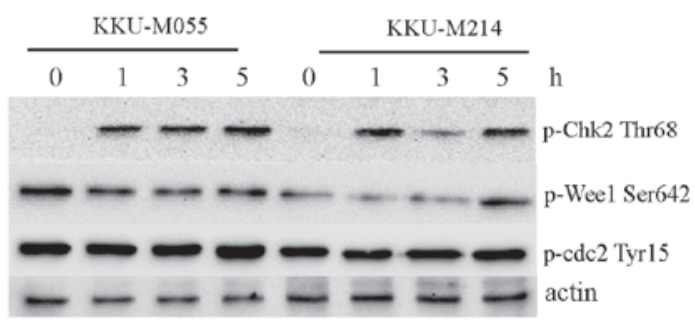

C

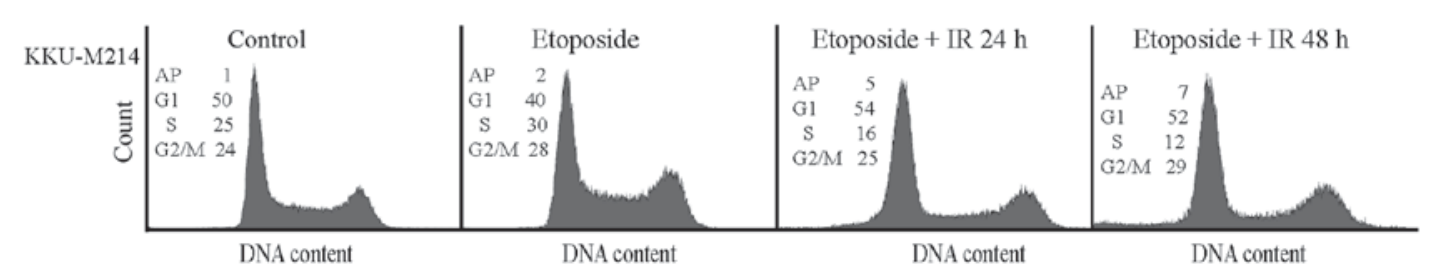

Figure 4. Effects of etoposide on the DNA damage response pathways in KKU-M055 and KKU-M214 cells. The cells were treated with 4 Gy X-rays or etoposide alone $(0.05 \mu \mathrm{g} / \mathrm{ml})$ or pretreated with etoposide for $24 \mathrm{~h}$ prior to X-ray irradiation. The cells were collected at different time points for protein extraction and cell cycle analysis. (A) The levels of p53, p-p53 Ser15 and p21 in extracts of KKU-M055 and KKU-M214 cells, following etoposide treatment were determined by western blot analysis. (B) The levels of relevant proteins for G2 checkpoint signaling in extracts of KKU-M055 and KKU-M214 cells following etoposide treatment were determined by western blot analysis. The detection of actin was used as a loading control. (C) Cell cycle distribution profiles were analyzed by flow cytometry. The numbers in the histograms indicate the percentages of the cells in each phase of the cell cycle $\left(\mathrm{G}_{1}, \mathrm{~S}\right.$ and $\left.\mathrm{G}_{2} / \mathrm{M}\right)$ or AP. IR, irradiation; p-p53 Ser15, tumor protein p53 phosphorylated at Ser15; p21, cyclin-dependent kinase inhibitor 1A; p-Chk Thr68, checkpoint kinase 2 phosphorylated at Thr68; Wee1, Wee1-like protein kinase; Cdc2, cyclin-dependent kinase 1; AP, aneuploidy. 

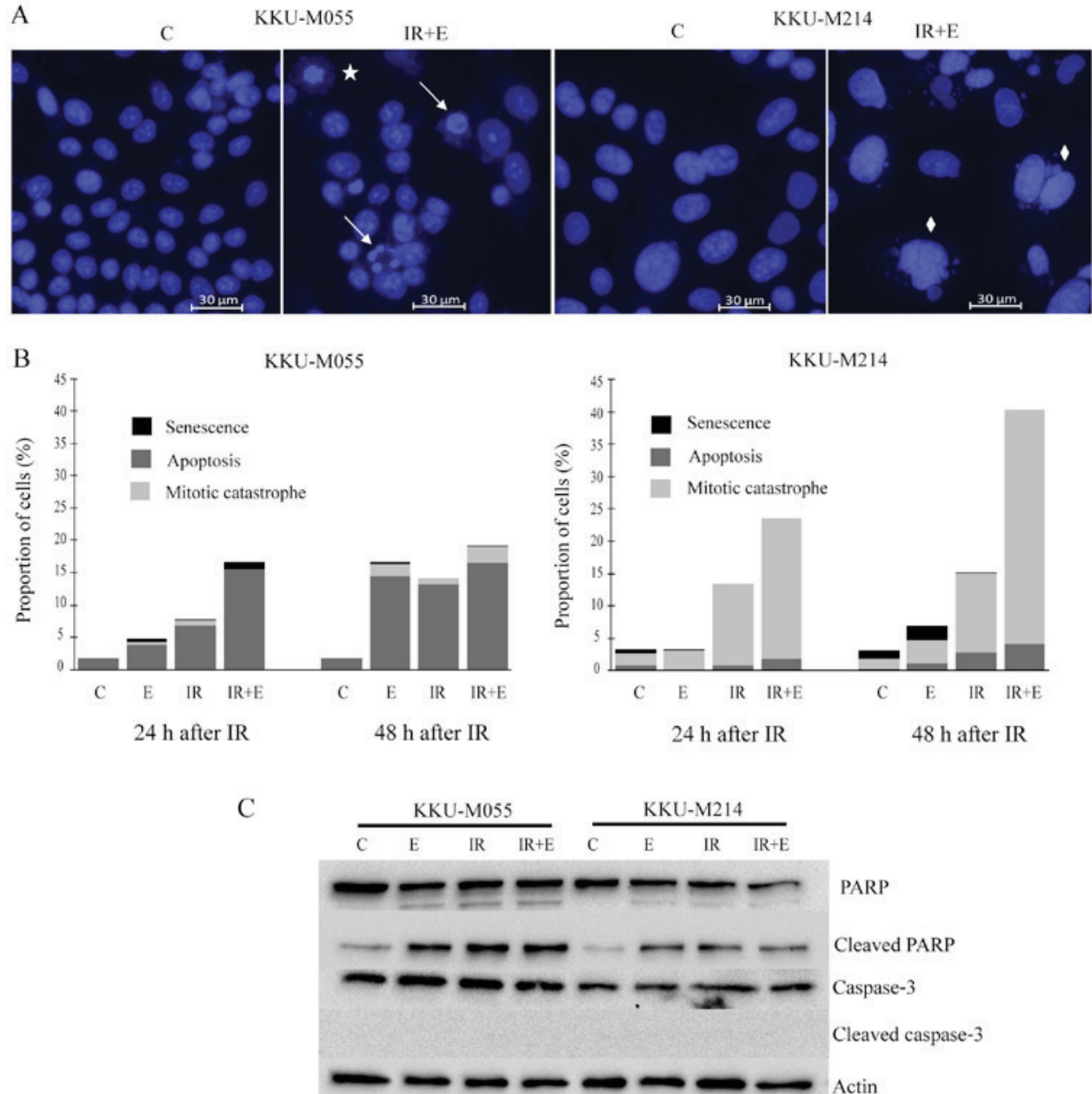

Figure 5. Distinct modes of cell death induced by etoposide or radiation or a combination thereof in KKU-M055 and KKU-M214 cells. The cells were pretreated with $0.05 \mu \mathrm{g} / \mathrm{ml}$ etoposide for $24 \mathrm{~h}$. Subsequently, the cells were irradiated with X-rays (4 Gy) or left without irradiation. The control cells were neither treated with etoposide nor irradiated. After 24 and $48 \mathrm{~h}$, the cells were stained with Hoechst 33342. Apoptosis, mitotic catastrophe or senescence was identified as described in the Materials and methods. (A) Representative images of nuclear staining with Hoechst 33342 indicates apoptotic (arrows), mitotic catastrophic (diamonds) and senescent cells (star). (B) The frequencies of apoptosis, mitotic catastrophe and senescence were quantified by fluorescence microscopy of Hoechst 33342 nuclear-stained cells. (C) Levels of key apoptotic proteins were determined by western blot analysis. The detection of actin was used as a loading control C, control cells; E, cells treated with etoposide; IR, irradiation; PARP, poly (ADP-ribose) polymerase; IR+ET, cells treated with a combination of X-rays and etoposide.

$48 \mathrm{~h}$ following irradiation (Fig. 2A). This result indicates a defective $\mathrm{G}_{2}$ checkpoint in KKU-M214 cells in response to radiation damage. Slight inductions of phospho-Chk2 Thr68, phospho-Cdc2 Tyr15 and cyclin B1 were observed in KKU-M214 cells (Fig. 2B and C). The induction of phosphorylation of Weel at Ser642 was not observed. These findings indicated a defect in the $\mathrm{G}_{2}$ checkpoint in KKU-M214 cells. It is unlikely that the partial activation of the p53-p21 axis in response to radiation is associated with the $G_{2}$ checkpoint functions of KKU-M214 cells.

Effect of etoposide on the radiation sensitivity of KKU-M055 and $K K U-M 214$ cells. The aforementioned results indicate the presence of an effective $\mathrm{G}_{2}$ checkpoint in KKU-M055 cells, but a defective $\mathrm{G}_{2}$ checkpoint in KKU-M214 cells. The effect of etoposide on the radiation sensitivity of KKU-M055 and KKU-M214 cells was therefore investigated. The y-intercepts of the survival curves (fitted trend lines) of KKU-M055 cells for irradiation alone, irradiation with $0.025 \mu \mathrm{g} / \mathrm{ml}$ etoposide, and irradiation with $0.05 \mu \mathrm{g} / \mathrm{ml}$ etoposide were $1.00,0.99$ and 0.68 , respectively (Fig. 3A). The y-intercepts of the survival curves (fitted trend lines) of KKU-M214 cells for irradiation alone, irradiation with $0.025 \mu \mathrm{g} / \mathrm{ml}$ etoposide, and irradiation with $0.05 \mu \mathrm{g} / \mathrm{ml}$ etoposide were $1.00,1.00$ and 0.80 , respectively (Fig. 3B).

The clonogenic survival of KKU-M055 cells following irradiation was decreased by pre-treatment with etoposide at concentrations of 0.025 and $0.05 \mu \mathrm{g} / \mathrm{ml}$ (Fig. 3A). A D37 value of 3.62 Gy was observed in KKU-M055 cells that were not pre-treated with etoposide. Pre-treatment of KKU-M055 cells with 0.025 or $0.05 \mu \mathrm{g} / \mathrm{ml}$ of etoposide reduced the D37 value to 2.42 or $1.05 \mathrm{~Gy}$, respectively. Thus, etoposide pre-treatment significantly enhanced radiosensitivity of KKU-M055 cells (ANOVA test for the presence of a difference in $\mathrm{D} 37$ mean values, $\mathrm{P}=0.00002$; post hoc values for $0.025 \mu \mathrm{g} / \mathrm{ml}$ etoposide or $0.05 \mu \mathrm{g} / \mathrm{ml}$ etoposide pre-treatment groups vs. irradiation alone treatment group, $\mathrm{P}=0.00122$ or $\mathrm{P}=0.00002$, respectively). A D37 value of 2.92 Gy was observed in KKU-M214 cells that were not pre-treated with etoposide. Pre-treatment of KKU-M214 cells with 0.025 or 
$0.05 \mu \mathrm{g} / \mathrm{ml}$ of etoposide reduced the D37 value to 2.61 or $1.51 \mathrm{~Gy}$, respectively (Fig. 3B). These cells were also significantly radiosensitized by etoposide pre-treatment (ANOVA test for the presence of a difference in D37 mean values, $\mathrm{P}=0.00001$; post hoc values of 0.025 or $0.05 \mu \mathrm{g} / \mathrm{ml}$ etoposide pre-treatment groups vs. irradiation alone, $\mathrm{P}=0.04458$ or $\mathrm{P}=0.00002$, respectively).

Data from the cell survival assay indicated that the radiosensitization activity of etoposide was most potent and significant at a concentration of $0.05 \mu \mathrm{g} / \mathrm{ml}$. Therefore, a concentration of $0.05 \mu \mathrm{g} / \mathrm{ml}$ etoposide was used in cell cycle analysis, western blot analysis and nuclear staining experiments.

Effect of etoposide on the DNA damage response pathway of $K K U-M 055$ and $K K U-M 214$ cells. The aforementioned results demonstrate the radiosensitizing property of etoposide on KKU-M055 and KKU-M214 cells. Thus, the effect of etoposide on the DNA damage response pathway of KKU-M055 and KKU-M214 cells was investigated (Fig. 4A and B). Treatment of KKU-M055 cells with $0.05 \mu \mathrm{g} / \mathrm{ml}$ etoposide did not induce expression of $\mathrm{p} 53$ or $\mathrm{p} 21$, or the phosphorylation of p53 at Ser15. This result indicates a non-functional p53-p21 axis in response to etoposide in KKU-M055 cells. Treatment of KKU-M214 cells with etoposide did not induce p53 expression. However, the induction of phosphorylation of p53 at Ser15, phosphorylation of Chk2 at Thr68 and expression of p21 were evident. These findings indicated a partial activation of the p53-p21 axis in KKU-M214 cells in response to etoposide treatment. The induction of phosphorylation of Chk 2 at Thr68 was clearly observed in the two cell lines. However, the levels of phospho-Wee1 Ser642, and phospho-Cdc2 did not markedly increase following etoposide treatment in the two cell lines. Therefore, it is unlikely that etoposide contributed to $G_{2}$ checkpoint activation in these cells.

The cell cycle distribution profiles demonstrate that etoposide induced a S-phase delay in KKU-M055 cells. Combined treatment with $0.05 \mu \mathrm{g} / \mathrm{ml}$ etoposide and 4 Gy X-rays induced the accumulation of KKU-M055 cells at the $\mathrm{G}_{2} / \mathrm{M}$ phase as determined at 24 and $48 \mathrm{~h}$ following irradiation. By contrast, treatment of KKU-M214 cells with etoposide alone or in combination with radiation only had a minor impact on cell cycle distribution (Fig. 4C).

Distinct modes of cell death are induced by etoposide or radiation or a combination thereof in KKU-M055 and KKU-M214 cells. The effect of etoposide on radiation-induced cell death in KKU-M055 and KKU-M214 cells was investigated further. The cells were exposed to $\mathrm{X}$-rays, etoposide, or a combination of X-ray irradiation and etoposide. The mode of cell death was evaluated according to the nuclear morphological characteristics as described in materials and methods. The results revealed that apoptosis was the dominant mode of cell death in KKU-M055 cells (Fig. 5A and B), whereas mitotic catastrophe was the dominant mode of cell death in KKU-M214 cells (Fig. 5A and B). Poly (ADP-ribose) polymerase cleavage was clearly observed in KKU-M055 and KKU-M214 cells following treatment with either X-rays or etoposide, or the combined treatment of X-ray irradiation and etoposide (Fig. 5C). No reduction in full-length caspase 3 was observed, which fits well with the absence of cleaved caspase 3 (Fig. 5C). This result indicates that cell death induced by etoposide or X-rays, or a combination thereof, is caspase-independent.

\section{Discussion}

Resistance of cancer cells to radiation is the most important reason for treatment failures of radiation therapy $(1,2,24,25)$. The synthetic-lethal targeting of defective cell cycle checkpoints could enhance the sensitivity of cancer patients to radiation $(9,11,12)$. However, identification of individual patient's tissue checkpoint defects is not practical in the clinic. The present study demonstrated that etoposide radiosensitizes p53-defective CCA cell lines, independent of their $\mathrm{G}_{2}$ checkpoint competencies.

The p53 protein serves a notable role in the regulation of cell cycle checkpoints and cell death pathways (25-27). p53 is crucial for $\mathrm{G}_{1}$ checkpoint induction but less essential for G2 checkpoint regulation (28-30). It was previously reported that KKU-M055 and KKU-M214 cell lines expressing a truncated p53 protein are defective in $\mathrm{G}_{1}$ checkpoint control (10). Expression of a truncated p53 protein was also indicated in the present study by western blot analyses. Extracts of immortalized normal human cholangiocyte cells (MMNK1) and human cervical carcinoma cells ( $\mathrm{SiHa}$ ) were used as reference material to display full-length p53 bands in western blot experiments $(16,17)$. A limitation of the present study is that there was no data of control experiments with CCA cell line expressing full-length $\mathrm{p} 53$.

In the present study, it was revealed that KKU-M055 cells possess an effective $G_{2}$ checkpoint. Effectiveness of the $G_{2}$ checkpoint of KKU-M055 cells was depicted by the marked accumulation of cells at the $\mathrm{G}_{2} / \mathrm{M}$ phase, together with the induction of Chk2, Wee1 and Cdc2 phosphorylation following irradiation. However, the activation of the p53-p21 axis in response to radiation in KKU-M055 cells could not be detected. This finding indicates that the $G_{2}$ checkpoint of KKU-M055 cells is activated independent of the p53-p21 axis. By contrast, the presence of a defective $G_{2}$ checkpoint was clearly demonstrated in KKU-M214 cells. These cells failed to halt the cell cycle at the $\mathrm{G}_{2} / \mathrm{M}$ phase following irradiation. The induction of p53 phosphorylation was observed following radiation. However, p53 phosphorylation did not contribute to the induction of cell cycle arrest in KKU-M214 cells at the $\mathrm{G}_{2} / \mathrm{M}$ phase. The present study demonstrated a radio-sensitizing effect of etoposide in CCA cell lines, which are p53- and $\mathrm{G}_{1}$ checkpoint-defective. Evidence indicates that different $\mathrm{p} 53$ defects exhibit distinct p53 activities $(26,31)$. The association between the radiosensitizing effects of etoposide and different functional p53 proteins requires clarification.

Etoposide is a highly active inducer of DNA double strand breaks and $\mathrm{G}_{2}$ arrest in mammalian cells $(14,15)$. No $\mathrm{G}_{2} / \mathrm{M}$ arrest was observed following the exposure of the two CCA cell lines to etoposide alone. Incubation of KKU-M055 cells (which have an intact $\mathrm{G}_{2}$ checkpoint) with etoposide prior to irradiation markedly increased the percentage of the cells in the $\mathrm{G}_{2} / \mathrm{M}$ phase compared with irradiation alone. However, the increased induction of $\mathrm{G}_{2} / \mathrm{M}$ arrest by etoposide was not observed in KKU-M214 cells (defective $\mathrm{G}_{2}$ checkpoint). Etoposide and radiation had a synergistic effect on the survival 
of the two CCA cell lines, regardless of their $\mathrm{G}_{2}$ checkpoint functionalities. Thus, it can be postulated that the $\mathrm{G}_{2} / \mathrm{M}$ arrest is not the determinant mechanism for the radiosensitization activity of etoposide.

The mechanism by which etoposide radiosensitizes the two CCA cell lines may be associated with the promotion of cell death. Etoposide may promote cell death by generating DNA double strand breaks within the cells prior to irradiation. The existing DNA double strand breaks would render the cell more vulnerable to the killing effects of radiation. To investigate this hypothesis, DNA damage could be quantified by analyzing well-defined markers of DNA damage such as $\gamma$-histone $\mathrm{H} 2 \mathrm{AX}$ or p53-binding protein 1 in future research projects. In the present study, it was indicated that the treatment of the cells of the two cell lines with etoposide prior to irradiation increased cell death without altering the dominant modes of cell death. Apoptosis and mitotic catastrophe are the principal modes of cell death in radiation-damaged cells (2). Following irradiation, cancer cells with $\mathrm{G}_{2}$ checkpoint defects cannot complete the repair of DNA damage before entering into mitosis. The cells subsequently attempt to divide and subsequently die through mitotic catastrophe (32). The findings from previous (10) and present studies indicate that $p 53$ and $G_{1}$ checkpoint functions are impaired in the two CCA cell lines. Therefore, it is likely that $\mathrm{G}_{2}$ checkpoint functionality determines the modes of cell death of these cells following irradiation. Apoptosis was found to be the dominant mode of cell death in KKU-M055 cells with an intact $\mathrm{G}_{2}$ checkpoint, whereas mitotic catastrophe was the dominant mode of cell death in KKU-M214 cells with a defect in the $\mathrm{G}_{2}$ checkpoint.

It was previously reported that etoposide/5-fluorouracil/leucovorin combination treatment improved the overall survival of patients with advanced pancreatic or biliary cancer $(33,34)$. However, the success of this treatment regime is limited due to its toxicity. The present study used very low concentrations of etoposide $(0.025$ and $0.05 \mu \mathrm{g} / \mathrm{ml} ;<0.1 \mu \mathrm{M})$ and revealed clear radiosensitization effects of etoposide on the two cell lines. This finding indicates that low concentrations of etoposide could be used as a low cytotoxic radiosensitizer for the treatment of CCA patients.

According to data from the SIB Bioinformatics Resource Portal ExPASy, the KKU-M214 cell line is a KKU-M213 cell line derivative (35). A contamination of the KKU-M214 cell line with KKU-M213 cells cannot be excluded in the present study. The current study investigated radio-sensitizing effects of etoposide on two cell populations differing in their $\mathrm{G}_{2}$ checkpoint status and clearly indicated that the two cell populations differ in this status. The two cell populations were sensitized by etoposide to undergo radiation-induced cell death. Thus, interpretation of the study results would not differ if the KKU-M214 cell line were in fact a mixed intrahepatic CCA type.

In conclusion, the intrinsic radioresistance of cancer cells is a core obstacle to the success of radiation treatment. The efficiency of radiotherapy can be improved by enhancing the radiosensitivity of cancer cells in vivo. The present study demonstrated the radiosensitizing effect of etoposide on two p53-defective CCA cell lines with either an intact or a defective $\mathrm{G}_{2}$ checkpoint. This provides good evidence that etoposide can be used as a radiosensitizer for tumors, independent of the functionalities of their $\mathrm{G}_{2}$ checkpoints.

\section{Acknowledgements}

The present study was supported by Naresuan University research fund (grant no. R2558C122).

\section{References}

1. Delaney G, Jacob S, Featherstone C and Barton M: The role of radiotherapy in cancer treatment: Estimating optimal utilization from a review of evidence-based clinical guidelines. Cancer 104: 1129-1137, 2005.

2. Maier P, Hartmann L, Wenz F and Herskind C: Cellular pathways in response to ionizing radiation and their targetability for tumor radiosensitization. Int J Mol Sci 17: E102, 2016.

3. Malik A, Sultana M, Qazi A, Qazi MH, Parveen G, Waquar S, Ashraf AB and Rasool M: Role of natural radiosensitizers and cancer cell radioresistance: An update. Anal Cell Pathol (Amst) 2016: 6146595, 2016.

4. Wang $H$, Zhang $X$, Teng L and Legerski RJ: DNA damage checkpoint recovery and cancer development. Exp Cell Res 334: 350-358, 2015.

5. Morgan MA and Lawrence TS: Molecular pathways: Overcoming radiation resistance by targeting DNA damage response pathways. Clin Cancer Res 21: 2898-2904, 2015.

6. Visconti R, Della Monica R and Grieco D: Cell cycle checkpoint in cancer: A therapeutically targetable double-edged sword. J Exp Clin Cancer Res 35: 153, 2016.

7. Deckbar D, Jeggo PA and Löbrich M: Understanding the limitations of radiation-induced cell cycle checkpoints. Crit Rev Biochem Mol Biol 46: 271-283, 2011.

8. Schmitt CA: Senescence, apoptosis and therapy-cutting the lifelines of cancer. Nat Rev Cancer 3: 286-295, 2003.

9. Gabrielli B, Brooks K and Pavey S: Defective cell cycle checkpoints as targets for anti-cancer therapies. Front Pharmacol 3: 9 , 2012.

10. Hematulin A, Sagan D, Sawanyawisuth K, Seubwai W and Wongkham S: Association between cellular radiosensitivity and G1/G2 checkpoint proficiencies in human cholangiocarcinoma cell lines. Int J Oncol 45: 1159-1166, 2014.

11. Koniaras K, Cuddihy AR, Christopoulos H, Hogg A and O'Connell MJ: Inhibition of Chk1-dependent G2 DNA damage checkpoint radiosensitizes p53 mutant human cells. Oncogene 20: 7453-7463, 2001.

12. Dillon MT, Good JS and Harrington KJ: Selective targeting of the $\mathrm{G} 2 / \mathrm{M}$ cell cycle checkpoint to improve the therapeutic index of radiotherapy. Clin Oncol (R Coll Radiol) 26: 257-265, 2014.

13. Lee JM and Bernstein A: p53 mutations increase resistance to ionizing radiation. Proc Natl Acad Sci USA 90: 5742-5746, 1993.

14. Thakur DS: Topoisomerase II inhibitors in cancer Treatment. Int J Pharma Sci Nanotechnol 3: 1173-1181, 2011.

15. Schonn I, Hennesen J and Dartsch DC: Cellular responses to etoposide: Cell death despite cell cycle arrest and repair of DNA damage. Apoptosis 15: 162-172, 2010.

16. Maruyama M, Kobayashi N, Westerman KA, Sakaguchi M, Allain JE, Totsugawa T, Okitsu T, Fukazawa T, Weber A, Stolz DB, et al: Establishment of a highly differentiated immortalized human cholangiocyte cell line with SV40T and hTERT. Transplantation 77: 446-451, 2004.

17. Lee YS, Bae SM, Kwak SY, Park DC, Kim YW, Hur SY, Park EK, Han BD, Lee YJ, Kim CK, et al: Cell cycle regulatory protein expression profiles by adenovirus p53 infection in human papilloma virus-associated cervical cancer cells. Cancer Res Treat 38: 168-177, 2006.

18. Hematulin A, Sagan D, Eckardt-Schupp F and Moertl S: NBS1 is required for IGF-1 induced cellular proliferation through the Ras/Raf/MEK/ERK cascade. Cell Signal 20: 2276-2285, 2008

19. Amornwichet N, Oike T, Shibata A, Ogiwara H, Tsuchiya N, Yamauchi M, Saitoh Y, Sekine R, Isono M, Yoshida Y, et al: Carbon-ion beam irradiation kills X-ray-resistant p53-null cancer cells by inducing mitotic catastrophe. PLoS One 9: e115121, 2014.

20. Vakifahmetoglu H, Olsson M and Zhivotovsky B: Death through a tragedy: Mitotic catastrophe. Cell Death Differ 15: 1153-1162, 2008 . 
21. Fei $P$ and El-Deiry WS: P53 and radiation responses. Oncogene 22: 5774-5783, 2003.

22. Obchoei S, Weakley SM, Wongkham S, Wongkham C, Sawanyawisuth K, Yao Q and Chen C: Cyclophilin A enhances cell proliferation and tumor growth of liver fluke-associated cholangiocarcinoma. Mol Cancer 10: 102, 2011.

23. Wattanawongdon $\mathrm{W}$, Hahnvajanawong $\mathrm{C}$, Namwat $\mathrm{N}$, Kanchanawat S, Boonmars T, Jearanaikoon P, Leelayuwat C, Techasen A and Seubwai W: Establishment and characterization of gemcitabine-resistant human cholangiocarcinoma cell lines with multidrug resistance and enhanced invasiveness. Int $\mathbf{J}$ Oncol 47: 398-410, 2015.

24. Hematulin A, Meethang S, Ingkaninan K and Sagan D: Derris scandens Benth extract potentiates radioresistance of Hep-2 laryngeal cancer cells. Asian Pac J Cancer Prev 13: 1289-1295, 2012.

25. Morrison R, Schleicher SM, Sun Y, Niermann KJ, Kim S, Spratt DE, Chung CH and Lu B: Targeting the mechanisms of resistance to chemotherapy and radiotherapy with the cancer stem cell hypothesis. J Oncol 2011: 941876, 2011.

26. Mirzayans R, Andrais B, Scott A and Murray D: New insights into p53 signaling and cancer cell response to DNA damage: Implications for cancer therapy. J Biomed Biotechnol 2012: 170325, 2012.

27. Speidel D: The role of DNA damage responses in $\mathrm{p} 53$ biology. Arch Toxicol 89: 501-517, 2015.

28. Chung JH and Bunz F: Cdk2 is required for p53-independent G2/M checkpoint control. PLoS Genet 6: e1000863, 2010.
29. Passalaris TM, Benanti JA, Gewin L, Kiyono T and Galloway DA: The $\mathrm{G}(2)$ checkpoint is maintained by redundant pathways. Mol Cell Biol 19: 5872-5881, 1999.

30. Sancar A, Lindsey-Boltz LA, Unsal-Kaçmaz K and Linn S: Molecular mechanisms of mammalian DNA repair and the DNA damage checkpoints. Annu Rev Biochem 73: 39-85, 2004.

31. Wasylishen AR and Lozano G: Attenuating the p53 pathway in human cancers: Many means to the same end. Cold Spring Harb Perspect Med 6: a026211, 2016.

32. Kim BM, Hong Y, Lee S, Liu P, Lim JH, Lee YH, Lee TH, Chang KT and Hong Y: Therapeutic implications for overcoming radiation resistance in cancer therapy. Int J Mol Sci 16: 26880-26913, 2015.

33. Rao S, Cunningham D, Hawkins RE, Hill ME, Smith D, Daniel F, Ross PJ, Oates J and Norman AR: Phase III study of 5FU, etoposide and leucovorin (FELV) compared to epirubicin, cisplatin and 5FU (ECF) in previously untreated patients with advanced biliary cancer. Br J Cancer 92: 1650-1654, 2005.

34. Glimelius B, Hoffman K, Sjödén PO, Jacobsson G, Sellström H, Enander LK, Linné T and Svensson C: Chemotherapy improves survival and quality of life in advanced pancreatic and biliary cancer. Ann Oncol 7: 593-600, 1996.

35. SIB Bioinformatics Resource Portal (ExPASy): Cellosaurus KKU-M214 (CVCL_M264). http://web.expasy.org/cellosaurus/CVCL_M264. Accessed August 9, 2017 